\title{
Consórcio Público de Saúde como arranjo para relação federativa e o processo de regionalização
}

\author{
Fernanda Freitas Mendonça \\ Universidade Estadual de Londrina \\ Silvia Karla Azevedo Vieira Andrade \\ Universidade Estadual de Londrina
}

\section{Resumo}

A relação federativa e a regionalização são dimensões relevantes para a organização de arranjos de cooperação no âmbito do desenvolvimento dos territórios, possibilitando o fortalecimento do federalismo, respeitando a autonomia municipal e vislumbrando o estabelecimento de relações de interdependência entre estes gestores. Nesse sentido, o consórcio público de saúde encontra-se posicionado como uma ferramenta estratégica. Ao longo da história do federalismo no Brasil, esses arranjos foram previstos nas constituições brasileiras, mas ocuparam espaços de pouco destaque no que tange à organização territorial e política no país. Diante desse cenário, desenvolveu-se um estudo de natureza qualitativa, com dimensão exploratória e investigativa, que teve como sujeitos os atores da gestão em saúde no âmbito municipal de uma região, além de representantes da gestão estadual, do consórcio e do Ministério da Saúde. O local de estudo foi a região de saúde do Médio Paranapanema, na macrorregião Norte do Paraná. A coleta de dados se deu por meio de entrevistas e grupos focais no primeiro trimestre de 2017, com roteiros semiestruturados e a metodologia de análise adotada foi a análise do discurso. Os resultados do presente estudo mostram que, após o Decreto Federal $n^{\circ} 7508 / 2011$, surgem novas perspectivas de fortalecimento da regionalização, em que os consórcios públicos de saúde podem se configurar com um papel inovador no elenco das prioridades territoriais das regiões de saúde, da tomada de decisões no âmbito regional e na construção de uma identidade coletiva em meio às necessidades dos entes.

Palavras-chave: Regionalização. Consórcio Público de Saúde. Federalismo. 


\title{
Public Health Consortia as an arrengement to the federative relation and the process of regionalization
}

\begin{abstract}
The federative relationship and regionalization are relevant dimensions to the organization of cooperation arrangements in the development of the territories, allowing for the strengthening of federalism, respecting the municipal autonomy and point out to the establishment of independence relations between these managers. In this sense, the public health consortia is positioned as a strategic tool. Throughout the history of federalism in Brazil, these arrangements were foreseen in the Brazilian constitutions, but occupied spaces of little prominence regarding the territorial and political organization in the country. Considering this scenario, a qualitative study was developed, with an exploratory and investigative dimension, which had as main subjects the actor from municipal health management on the scope of a region, as well as representatives of state management, consortia and Ministry of Health. The study site was the health area of the Middle Paranapanema, in the northern macroregion of Paraná. Data collection was done through interviews and focus groups in the first quarter of 2017, with semi-structured scripts and the analysis methodology adopted was the discourse analysis. The results of the present study show that, after Federal Decree 7508/2011, new perspectives for strengthening regionalization emerge, in which public health consortia can be configured with an innovative role in the list of territorial priorities of the health, regional decision-making and the construction of a collective identity in the midst of the needs of the entities.
\end{abstract}

Keywords: Regional Health Planning. Health Consortia. Federalism.

\section{Consorcio de Salud Pública como arrendamiento de la relación federativa y el proceso de regionalización}

\section{Resumen}

La relación federativa y la regionalización son dimensiones relevantes para la organización de arreglos de cooperación en el ámbito del desarrollo de los territorios, posibilitando el fortalecimiento del federalismo, respetando la autonomía municipal y vislumbrando relaciones de interdependência entre estos gestores. En este sentido, el consorcio público de salud se encuentra posicionado como una herramienta estratégica. A lo largo de la historia del federalismo en Brasil, esos arreglos fueron previstos en las constituciones brasileñas, pero ocuparon espacios de poco destaque en lo que se refiere a su organización territorial y política. En este contexto, se desarrolló un estudio de naturaleza cualitativa, con dimensión exploratoria e investigativa, que tuvo como sujetos a los actores de la gestión en salud en el ámbito municipal de una región, además de representantes de la gestión estadual, del consorcio y del Ministerio de Salud. El local de estudio fue la región del Medio Paranapanema, en la macroregión Norte del Paraná. La recolección de datos se dio a través de entrevistas y grupos focales en el primer trimestre de 2017, con itinerarios semiestructurados y la metodología de análisis adoptada fue el análisis del discurso. Los resultados muestran que, después del Decreto Federal $n^{\circ} 7508 / 2011$, surgen nuevas perspectivas de fortalecimiento de la regionalización, en que los consorcios públicos de salud pueden configurarse con un papel innovador en el elenco de las prioridades territoriales, la toma de decisiones en el ámbito regional y la construcción de una identidad colectiva en medio de necesidades de los entes.

Palavra Clave: Regionalización. Consorcios de Salud. Federalismo. 


\section{Introdução}

A relação federativa é essencialmente dialógica e necessita ser estudada no intuito de contribuir para a implantação de políticas públicas, no âmbito do desenvolvimento regional dos territórios. Uma das áreas relevantes para a organização de arranjos de cooperação que fomentem a relação federativa é a da saúde pública, que possui princípios garantidos pela Constituição Federal - CF de 1988 para a institucionalização da participação social em todas as esferas de gestão (BRASIL, 1988).

Nesse sentido, os Consórcios Públicos de Saúde - CPS, previstos na constituição e nas Normativas Operacionais Básicas - NOB, que são parte do arcabouço legal e estruturante do Sistema Único de Saúde - SUS, conferem uma nova perspectiva de cooperação federativa e solidária entre entes federados e apresentam-se como uma forma de associação para superar as deficiências de escala, além de instrumento de formalização contratual, para captar, agregar e/ou gestionar recursos (VAZ, 1997; PRATES, 2012b).

Esses arranjos organizativos por meio de CPS promovem a interação entre os níveis assistenciais, sendo um grande passo para a garantia do acesso e de interação entre os serviços públicos de saúde, de forma equitativa e em benefício dos municípios de diferentes portes, fomentando o processo de regionalização, ainda não consolidado no SUS (PINAFO, 2016). Com isso, foi possível reduzir as desigualdades regionais, por meio da conjugação federativa de esforços (LIMA, 2000).

Ademais, por meio dos CPSs, os gestores dos pequenos municípios podem efetivar sua autonomia frente ao processo de descentralização, com responsabilização compartilhada, favorecendo a ação solidária e cooperativa entre os entes federados, induzindo-os à congregação de esforços (ROCHA, 2016). Esse histórico de sucesso na experiência da ação consorciada também se apresentou em outros países, sobretudo na Europa, em razão de um cenário de debilidade fiscal e administrativa (PRATES, 2012a).

No Brasil, os CPSs surgiram em meados da década de 1980, no interior do Estado de São Paulo, por iniciativa de gestores municipais e, para regulamentar esta organização, advém a Lei Federal n 11.107/2005 (BRASIL, 2005), conhecida como a Lei dos Consórcios, regulamentada pelo Decreto Federal $n^{\circ}$ 6.107/2007 (BRASIL, 2007), que estabelece critérios e diretrizes para a criação e funcionamento dos CPSs.

Esse arcabouço legal apresenta-se como instrumento recente no campo do Direito Administrativo e propõem mecanismos de articulação entre os entes federativos, provocando uma nova lógica para a atuação dos CPSs.

Com isso, no início dessa década, eram 2.903 os municípios participantes da ação consorciada, sendo 2.288 na área de saúde (BRASIL, 2011b), o que representa um processo de transição no cenário da gestão pública, que ratifica o processo de descentralização, mas, sobretudo, fomenta a territorialização e o processo de regionalização, com a congregação de territórios diante de suas especificidades territoriais.

Essa realidade requer um profundo discernimento acerca da atuação do CPS e novas reflexões acerca de suas potencialidades no momento atual, que propõe a 
passagem de um padrão competitivo entre os municípios para a construção de um sistema efetivamente cooperativo horizontal, por meio do fortalecimento das relações federativas (ROCHA; FARIA, 2004).

Diante disso, o objetivo deste estudo foi compreender a potencialidade do CPS no âmbito da regionalização e da relação federativa.

\section{Caminho percorrido}

O presente estudo tem abordagem qualitativa de caráter exploratório, descritivo e analítico, que favorece a exploração da potencialidade dos CPSs em meio às relações federativas. O estudo foi desenvolvido na Região de Saúde do Médio Paranapanema do Norte do Paraná, que congrega 21 municípios, e foram selecionados gestores da esfera municipal, estadual e federal e do CPS da região.

Os sujeitos do estudo foram classificados de acordo com sua função diante do coletivo e a estratégia de levantamento de dados foi entrevistas com os gestores dos municípios sede de microrregião, município sede de região, gestor estadual e federal e dirigente de consórcio e grupos focais nos demais municípios, classificados em dois grupos: a) municípios com base populacional de até 5,9 mil habitantes, e; b) municípios com base populacional entre 6 mil e 20 mil habitantes.

As entrevistas e os grupos focais foram gravados, transcritos literalmente e posteriormente analisados, após aplicação do Termo de Consentimento Livre e Esclarecido - TCLE entregues previamente e devidamente assinados, consentindo sua participação. O período de coleta de dados foi o primeiro trimestre de 2017.

A análise dos dados se deu a partir do método de análise do discurso, proposto por Martins e Bicudo (2003). O estudo atendeu aos requisitos éticos e à normativa inerente à pesquisa científica envolvendo seres humanos, de acordo com a Resolução 466/12 (BRASIL, 2012). O projeto de origem desse estudo foi submetido ao Comitê de Ética em Pesquisa da Universidade Estadual de Londrina e obteve aprovação (CAAE: 56868416.1.0000.5231).

\section{Resultados e discussão}

Esta seção apresenta os resultados do estudo e a discussão acerca da potencialidade dos CPS no contexto do desenvolvimento regional. Antes, porém, apresenta o embasamento teórico acerca do federalismo no histórico brasileiro e dos jogos sociais, os quais mostram que os resultados encontrados repetem movimentos de centralização e descentralização do poder por meio das relações federativas.

\subsection{O federalismo brasileiro e o contexto histórico de criação dos CPS}

Um importante aspecto da estruturação de arranjos organizativos que atendem às necessidades territoriais é a constituição do federalismo brasileiro no final do século XIX e a recente retomada do processo de redemocratização, que no âmbito da saúde, culminou na implantação do SUS.

O federalismo, segundo Harman (1992, p.37) "refere-se aos laços constitutivos de um povo e de suas instituições, construídos através de 
consentimento mútuo". A instituição do federalismo no Brasil ocorreu por meio da CF de 1891.

Nessa fase inicial, logo após a Proclamação da República, a organização político-administrativa advinda da herança do império e da coroa portuguesa fez com que a autoridade decisória se mantivesse no governo central e a CF permitia a destinação de recursos financeiros de maneira desigual para os governos subnacionais, favorecendo a concentração de recursos em alguns Estados, o que promoveu atritos na relação federativa (SOUZA, 2005; CUNHA, 2001).

Ao longo da construção histórica das relações federativas no Brasil, segundo discorre Souza (2005), houve alternância nos seus arranjos, quer sejam democráticos ou autoritários. Embora a relação de unidade entre os entes federados não se constituísse como tema de discussão ou problema a ser enfrentado, a heterogeneidade econômica entre as regiões tornou-se uma barreira significativa para o desenvolvimento do País (SOUZA, 2005).

Nos primeiros anos do federalismo, que foram marcados pela detenção do poder econômico, social e político pelos proprietários rurais, as preocupações relativas à saúde se davam em decorrência de questões econômicas, no sentido de manter a saúde dos trabalhadores para não prejudicar o avanço na produção e a exportação do café. Isso resultou na implantação das Caixas de Aposentadorias e Pensões que concediam a algumas classes trabalhadoras benefícios pecuniários e prestação de serviços médicos e farmacêuticos (CARVALHO et al, 2017). Com o advento da crise do café a partir de 1929, uma nova carta constitucional é redigida e o poder centralizado na União é fortalecido, de forma que o novo regime político fragiliza as relações federativas (HOCHMAN, 2005).

Com o advento da Ditadura no Estado Novo em 1937 e, posteriormente, com o Golpe Militar de 1964, as decisões eram tomadas de forma verticalizada, com características autoritárias e, do mesmo modo, o campo da saúde era caracterizado por um modelo também centralizador, marcado por decisões tecnocráticas e corporativistas e por um padrão de intervenção médica (LUZ, 1991).

Diante das inquietudes e impulsionado pelo pensamento crítico acerca das políticas de saúde, em meados da década de 1970, os movimentos sociais uniram-se a partir do conceito ampliado de democracia e funda-se o Movimento pela Reforma Sanitária, opondo-se ao golpe militar, em favor de uma política de saúde pública de qualidade para todos (CORDONI JR, 1979).

Nesse cenário de reformas, o relatório geral da $8^{a}$ Conferência Nacional de Saúde, construído por meio de participação popular, subsidia uma série de artigos da CF de 1988 e estabelece os princípios do SUS, fortalecendo o princípio federativo e a descentralização, conferindo autonomia político-administrativa aos municípios brasileiros, com obrigações específicas para o desenvolvimento de políticas sociais e ampliação de sua competência legislativa, com previsão de transferências de recursos federais. Dessa forma, os governos subnacionais assumiram progressivamente responsabilidades administrativas e econômicas sobre as políticas públicas (FLEURY, 2006; ARRETCHE, 2004).

A partir da NOB 96, os consórcios de saúde recebem a configuração de estratégias para articulação intermunicipal. O Ministério da Saúde refere-se aos consórcios e apresenta a necessidade de sua criação a partir do documento 1997 - O Ano da Saúde no Brasil (BRASIL, 1997a). No mesmo ano, convoca a primeira oficina 
sobre consórcios, editando o manual "Os Consórcios e a Gestão Municipal em Saúde", que aponta os consórcios como um mecanismo eficiente para elevar os municípios à Gestão Plena do Sistema Municipal de Saúde (BRASIL, 1997b). O documento apresenta o conceito de consórcio, sob ponto de vista jurídico e etimológico, como a união de entes da mesma natureza, não sendo "um fim em si mesmo, mas um meio para resolução de problemas e para alcance de objetivos comuns" (BRASIL, 1997b, p.7).

Frente a essa contextualização histórica, os resultados do estudo mostram que os sujeitos reiteram a verticalização na tomada de decisões, a distribuição de recursos financeiros de maneira desigual entre os entes federativos e a centralização do poder na união. Entretanto, também no momento atual, há evidências de adoção de estratégias para fortalecer a democracia e a relação federativa.

\subsection{Os jogos sociais e a complexidade nas relações federativas na Região de Saúde}

Tão importante como verificar o modo como as relações federativas foram se construindo e se reconstruindo ao longo da história, é também analisar de que modo tais relações se estabelecem e que tipo de produções são oriundas dessas relações. A partir das relações federativas, os atores sociais envolvidos na gestão se articulam e compartilham experiências, proporcionando um cenário no qual o planejamento se oportuniza e a tomada de decisão é possibilitada.

Nesse sentido, é essencial a compreensão acerca do sujeito, da formação do pensamento humano, para então posicioná-lo diante do outro, por meio da linguagem, abordando também o conceito de alteridade, pelo qual o sujeito se diferencia dos demais. Para compreender como se dá a formação do pensamento, o filósofo russo Bakhtin (1986 [1929]) aponta que a origem do pensamento e da atividade mental advém da linguagem, que está vinculada à expressão do sujeito.

Para Bakhtin, não é a atividade mental que organiza a expressão, mas, ao contrário, é a expressão que organiza a atividade mental, de forma que a consciência adquire forma no curso das relações sociais. Assim, há dois polos da atividade mental, a atividade mental do "eu" e a do "nós", sendo que esta última, se expressa de forma ideológica no contexto social, permite a firmeza e a estabilidade da orientação social (BAKHTIN, 1986 [1929]).

Dessa forma, a linguagem é condicionada pela organização social entre os indivíduos e pelas condições de sua interação social. Nesse contexto interacional é que ocorrem as relações sociais entre gestores de saúde e a partir desta análise é possível alcançar com mais profundidade como se dão as relações federativas no âmbito da região de saúde. Diante desse contexto, compreende-se que é por meio das relações federativas que gestores públicos têm oportunidade de construir uma atividade mental coletiva.

Entretanto, cabe ressaltar que o discurso empregado pelos atores sociais é baseado na subjetividade das relações, nas percepções culturais, no entendimento acerca de seu papel social, sua identidade e também no contexto social em que o mesmo se encontra, considerando sua alteridade, que pode ser entendida como a possibilidade de ver o outro como um sujeito relacional com sua singularidade, sua bagagem cultural, suas diferenças e suas subjetividades (BRASIL, 2006). 
Verificando-se como a linguagem e a subjetividade, por meio da interação social atuam no âmbito da gestão em saúde, torna-se necessário avançar para o entendimento acerca da alteridade, para que seja possível compreender o processo de tomada de decisões entre os gestores e como eles se posicionam de maneira distinta diante de um mesmo problema. Por meio da alteridade, permite-se o entendimento acerca do condicionamento dos atores sociais devido à sua formação pessoal, experiências vividas e percepção acerca de seu papel diante do coletivo.

Além disso, compreender esse conceito possibilita respeitá-lo por suas individualidades, mais ainda, permite deslocar aquele que o escuta de suas próprias certezas. Nesse mesmo entendimento acerca da alteridade, Segato (2006) acrescenta o impulso ético em relação ao outro como aquilo que nos permite "estranhar nosso próprio mundo", e aponta a dimensão ética da existência humana como sendo distinta da moralidade (que se refere aos costumes) e da legalidade (produto de negociação, que refere-se à conquista de um território por um vencedor em um jogo de forças, que implanta suas convicções).

Dessa forma, compreende-se que, por meio da interação com o outro, o gestor de saúde é conduzido a uma reflexão que o descola de si mesmo (SCHOLZE et al, 2009). Por meio da linguagem e da consequente construção do pensamento, considerando a alteridade, o impulso ético e a relação social com seus pares, o gestor municipal constrói novas percepções acerca de seu papel e das necessidades territoriais. A partir dessa prática participativa, é possível estabelecer novos caminhos para a efetivação de mecanismos cooperativos para o sistema de saúde.

Para compreender como funcionam as relações organizacionais, Srour (1998), sob enfoque das Ciências Sociais, descreve as organizações e as classifica de acordo com seu predomínio em três categorias: a) organizações predominantemente econômicas; b) organização públicas ou; c) organizações simbólicas. Com isso, ele ressalta que os membros das organizações são agentes coletivos, ou seja, contém seus estatutos e normativas e as representam empiricamente. Todo agente possui um conjunto de relações sociais, podendo apresentar diferentes interesses em jogo. Desse modo, Srour (1998) apresenta quatro diferentes modos de exercitar o poder, quais sejam: a) relação de dependência (modo autoritário), relação de sobredependência (modo totalitário), relação de independência (modo liberal) e relação de interdependência (modo democrático). Nas relações federativas, todos esses modos de exercício do poder podem ser representados.

No intuito de melhor entender as relações organizacionais que mostram o exercício do poder tendo a linguagem como meio, Matus (2005), por sua vez, ao analisar as relações de poder, apresenta a Teoria do Jogo Social - TJS, que enfoca a figura do gestor na administração pública. Ele ressalta que, por meio de relações interacionais, os atores sociais se expressam e isso ocorre através de diferentes jogos de elevado nível de complexidade, ressaltando que a interação se dá por meio da cooperação ou do conflito.

A teoria matusiana descreve o jogo social comparando-o a um jogo esportivo, com jogadores - atores sociais - e suas regras. Entretanto, enquanto no jogo esportivo existem regras que igualam as condições entre os jogadores, no jogo social as regras podem, muitas vezes, beneficiar a um e prejudicar a outro. Essas regras são variáveis e mudam de acordo com os interesses que estão em jogo. 
Nesse cenário, os atores sociais agem por meio de jogadas como forma de solucionar os problemas e exercer o poder sobre os demais, dominando os jogos. Com isso, por meio do jogo social, não é possível predizer o futuro ou prédeterminar vencedores, uma vez que não existem relações lineares, em que uma causa leva a uma consequência (MATUS, 2005).

De acordo com Matus (2005), esses jogos se dão de forma simultânea e em paralelo, acontecem no mesmo tempo e espaço físico, sendo que cada um deles possui sua própria dinâmica e envolvem três conceitos, quais sejam: problema, ator social e analise situacional. Ao relacionar esses conceitos à gestão em saúde, é possível compreender que o conceito de problema trata de uma situação que precisa ser solucionada. No jogo social, o poder é “(...) uma potencialidade que possibilita a acumulação de força” (MATUS, 2005, p. 409). Ele emana da desigualdade das regras do jogo e pode concretizar-se ou não em força, isso vai depender do código de personalidade do ator, da situação, dos oponentes, das circunstâncias do contexto, entre outros fatores.

Nesse sentido, Matus (2005, p. 367) ressalta ainda que a pessoa humana reúne necessidades e atributos únicos, de forma que a palavra "pessoa" está fortemente relacionada ao ator, aquele que executa um papel e que o torna distinto do abstrato. Ele relaciona à pessoa as expressões liberdade, justiça, igualdade, solidariedade, fraternidade, dignidade, afetos e emoções, sentido estético e moral.

No âmbito da gestão, o exercício da função pública é uma prática social e o gestor é agente transformador das realidades sociais. Dessa forma, o ator social é o protagonista do jogo social, o qual demanda conhecimento teórico acerca do jogo. Assim, verifica-se o quanto as relações federativas, se analisadas pelo foco das relações sociais e de poder são complexas.

Diante do cenário dos jogos sociais e da complexidade das relações federativas, avalia-se que, embora ao longo da história de criação e implementação dos CPSs estes tenham exercido diferentes papéis, tendo sido exaltados desde funções inerentes à prestação de serviços, até o papel de ferramenta para aumento de escala e potencialização de compra conjunta, não obstante o confundimento na execução desses papéis, há um grande potencial passível de desenvolvimento na atuação dos entes por ocasião da ação consorciada.

Os resultados do presente estudo evidenciam que, na experiência dos gestores municipais de saúde da região estudada, os consórcios atuam por meio de consensos, ressaltando sua representatividade por meio da ação consorciada. Com enfoque sobre essa realidade na gestão em saúde, o posicionamento da figura do CPS poderá representar um ponto de equilíbrio entre os jogadores, o que é considerado um cenário inovador nas relações federativas. É por meio da ação dos CPSs que, diante das relações de dependências de Srour (1998) e dos jogos de Carlos Matus (2005), o consórcio público de saúde pode oferecer estratégias para promoção das relações de interdependência no âmbito do interesse coletivo, podendo assumir identidades regionais, através das quais se constroem possibilidades de alcance de benefícios coletivos racionalmente planejados, de maneira cooperativa e solidária.

Com isso, o CPS é apontado pelos sujeitos do estudo como uma alternativa para o fortalecimento dos entes municipais, podendo melhor posicioná-los à frente dos jogos sociais e oportunizando a inversão dos papéis diante das relações de 
dependência por meio do compartilhar de saberes, experiências e estratégias, sob enfoque da ação coletiva e das necessidades do território regional.

Dessa forma, o consórcio fortalece não somente a descentralização, mas exalta a regionalização, combatendo a atomização e a sobrecarga municipal, o que favorece uma distribuição social de poder de forma mais igualitária (MELUCCl, 1996; FLEURY, 2006).

O processo de regionalização mostra-se ainda incipiente, uma vez que, em especial para as pequenas localidades, a luta diária acerca dos desafios do cotidiano, tendo em vista as limitações próprias dos territórios mais distantes dos grandes centros, com equipes em número limitado e maior dificuldade de acesso à informação e formação técnica. Todos esses fatores resultam em um desconhecimento dos gestores acerca de sua potência decisória.

Tendo em vista o processo de regionalização tratar-se de um "processo eminentemente político" (A18), ressalta-se a necessidade de busca de mecanismos e instrumentos que favoreçam a relação federativa, para que a regionalização se consolide de fato.

Ademais, ao longo da história de construção do SUS, houve momentos de fortalecimento da regionalização do ponto de vista político, alternando-se com momentos de operacionalização das ferramentas administrativas, apontando para um cenário fragmentado do conhecimento, com pouca possibilidade de continuidade neste processo.

Cumprem-se rituais, formalizações ou ocupam-se espaços sem a compreensão mais aprofundada acerca de sua finalidade, o que enfraquece as instâncias de discussões e de tomada de decisões. O processo de atualização normativa em saúde ocorre de forma centralizada, ainda que de maneira representativa. Entretanto, os gestores municipais não protagonizam esse processo, sendo apenas informados acerca dessas novas normativas. Nesse contexto, a atualização normativa executada de maneira centralizada e verticalizada demanda um esforço de assimilação pelos gestores municipais para sua consolidação.

Esse movimento de centralização é evidenciado pelas práticas de tomada de decisões e ações de iniciativa do governo central, que são compartilhadas e debatidas junto aos representantes dos estados e municípios, mas independem de discussão ascendente entre pares para que sejam aprovadas e estabelecidas. Isso remete às práticas do governo unitário, o que fragiliza o federalismo (MENDES, 1993; RABAT, 2002; ARRETCHE, 2004).

Além disso, há distanciamento dos gestores municipais de seus pares no processo decisório quando há necessidade de formulação de políticas públicas que atendam às necessidades regionais, mostrando uma afinidade maior entre os municípios demograficamente menores e o distanciamento destes com os municípios de maior base populacional.

Tendo em vista a necessidade de estruturação de um planejamento regional participativo, que se configure de fato ascendente, agregam-se fatores complicadores que limitam a gestão municipal e somam-se ainda fatores impeditivos de toda ordem. Um desses fatores ora apresentados é o posicionamento dos municípios em sua participação nos grupos temáticos, com pouca interação entre municípios de diferentes portes. 
Além disso, há uma auto percepção de desvantagem dos municípios menores em relação aos maiores, no que tange ao acesso, organização dos recursos financeiros, participação na formulação de políticas públicas, apontando que os municípios demograficamente pequenos são ainda "esquecidos" (A04).

Um aspecto que interfere na relação federativa e no entendimento acerca do conceito de região de saúde é a permanência de contextos que remontam às primeiras normativas do SUS acerca das condições de gestão do município e sua habilitação como gestor pleno do sistema municipal, como significado da declaração dos compromissos assumidos por parte do gestor perante os outros gestores em relação à população compreendida sob sua responsabilidade (BRASIL, 1996).

Os resultados mostram que gestores habilitados naquela ocasião, mantemse, mesmo após atualizações normativas, sendo mais recente o entendimento trazido no Decreto Federal $n^{\circ} 7.508 / 2011$ (BRASIL, 2011), requerindo sobre si a autoridade para tomada de decisões de forma individualizada, em substituição às instâncias regionais.

Ademais, uma limitação bastante preocupante é a possível submissão ou dominação entre municípios de diferentes portes ou posicionamentos, estabelecendo um sistema de dominação (SROUR, 1998). Essa relação de dominação pode se constituir considerando as diferenças existentes entre os atores da gestão, seu estilo de personalidade, atitudes de inferioridade ou superioridade, conhecimento ou desconhecimento técnico e da construção do SUS, circulação restrita de informações, entre outros.

Esse posicionamento individual em representação ao coletivo é percebido dentre os resultados do presente estudo como bastante comum no contexto das instâncias formais e informais de relação federativa, de forma que gestores municipais com maior porte decidem e demandam organizações de forma individualizada, a partir de definições que, por vezes, distam do interesse do coletivo.

Todas essas limitações decorrem das fragilidades nas relações federativas no território e de uma suposta fragmentação estabelecida pelo processo de municipalização (SANTOS; CAMPOS, 2015). Aponta-se ainda para a inexistência de proximidade e conhecimento mútuo das realidades locais, a inexistência de discussões acerca de projetos que atendam a interesses mútuos, o que impede a construção de uma relação no âmbito regional.

No que tange ao financiamento e sua [in]suficiência, há ainda o desconhecimento acerca da distribuição da totalidade do recurso gestionado na região de saúde e sua aplicação, como por exemplo, o distanciamento das informações acerca dos montantes contratualizados e metas pactuadas para o atendimento em hospitais de nível terciário referenciados para a região, o que dificulta a construção compartilhada.

Ressalta-se também a atualização das informações ao longo do tempo e a dificuldade de assimilação de novas discussões inerentes ao processo de construção do SUS, que possibilitam que se originem novos posicionamentos. Um exemplo disso está na nomenclatura empregada aos gestores municipais que assumiram a gestão e o planejamento regional de suas ações e serviços no início da década de 1990, por meio de processos de habilitação municipal. 
Esse processo de habilitação incluiu a gestão dos recursos financeiros repassados pela esfera federal diretamente aos municípios, de maneira fundo a fundo, conferindo autonomia aos gestores, articulados ao controle social, ainda hoje conhecidos por sua habilitação como gestor pleno do sistema de saúde.

No território de estudo, o município então habilitado naquela ocasião enfrenta dificuldades para empregar um olhar ampliado e solidário, do ponto de vista da região de saúde, considerando o escopo de suas responsabilidades territoriais. Além disso, considerando ser o município de maior visibilidade política na região, os municípios menores esperam que este assuma uma posição de liderança frente aos demais, o que, diante de sua perspectiva, proporcionaria benefícios para toda a região de saúde.

Essa forma de organização evidencia as relações de dependência e mostra sinais de apatia ou submissão das pequenas localidades diante de gestores com maior capacidade técnico-política-administrativa, de maneira que, na ausência de discussões ascendentes que originem o planejamento, resta aos gestores municipais a implantação das políticas estaduais e federais, o que enfraquece $o$ processo de regionalização e o federalismo.

Diante dos jogos de Carlos Matus (1994), o discurso empregado pelos sujeitos evidencia submissão e pouco diálogo e apresenta marcas de suas vulnerabilidades diante do jogo político e do jogo do conhecimento nas relações federativas. Essa vulnerabilidade e ausência de uma ação coletiva efetiva podem trazer consequências para a qualidade de vida das pessoas que dependem da gestão efetiva em saúde, havendo, portanto, necessidade de estruturação de um espaço de lutas comuns, em favor da região de saúde.

Os resultados expressam as mesmas características apresentadas no resgate histórico de centralização, de forma que, mesmo após as reformas constitucional e normativa recentes, ainda há fragilidades no processo de gestão democrática no País.

\subsection{A Potência do CPS para o Desenvolvimento Regional}

De acordo com o contexto explicitado até este ponto, o histórico de construção do SUS, inicialmente com o processo de municipalização e posteriormente com o impulsionamento da regionalização por meio da agregação de esforços e da organização de instâncias de articulação, como parte da tomada de decisões no âmbito da saúde pública, fez com que os municípios fossem incentivados ao exercício da relação federativa.

Entretanto, esses esforços não produziram efeitos que possibilitassem a consolidação do processo de regionalização, de maneira ascendente e cooperativa, que incentivassem a participação, em especial, dos pequenos municípios. Essas limitações apresentam-se devido à organização das instâncias de relação no âmbito regional, que, em geral, resumem-se ao repasse de informações e transmissão de instruções para implantação de políticas públicas de ordem estadual ou federal aos gestores municipais (NICOLETTO, 2015; PINAFO, 2016) e também pela incipiência na mobilização entre os atores estratégicos que possibilitem 0 incremento às capacidades técnicas, institucionais e políticas em prol da regionalização (LIMA et al, 2012). 
Nesse sentido, considerando a multiplicidade de papéis e potencialidades dos CPSs como apoiadores da ação coletiva, cujo papel é desenvolvido por meio da representatividade e da execução de programas voltados para o território regional (ANDRADE, 2018), é ressaltada a importância da utilização dessa ferramenta em benefício dos pequenos municípios, fomentando o desenvolvimento regional, a ser construído de forma ascendente e participativa, por meio de consensos, em lugar da implantação exclusiva de políticas de interesse federal ou estadual.

Diante dessa perspectiva, Melucci (1996) aborda a relação entre a ação coletiva e os movimentos sociais, apontando que nesta configuração, por meio de complexos processos de interação mediados pelas redes a que pertencem os atores, é possível promover mudanças nas relações e o estabelecimento de uma identidade regional.

Dessa forma, os CPSs aproximam-se dos movimentos sociais e da ação coletiva, sob enfoque das relações sistêmicas, por meio da interação de seus atores em relação aos objetivos e à gestão de recursos comuns. O CPS ladeia o ente municipal em sua busca por melhores condições de vida para sua população por meio da definição de prioridades, tendo em comum a luta pelo desenvolvimento territorial, que se constitui em sua identidade coletiva, sendo esta a capacidade de reconhecer a seus pares e ser reconhecido regionalmente como parte da mesma unidade social.

Essa organização territorial é prevista no Contrato Organizativo da Ação Pública - COAP junto ao Decreto Federal $n^{\circ}$ 7508/2011, tendo como elementos constituintes as Redes de Atenção à Saúde, constituídas de maneira horizontal nos territórios regionais, o Mapa Regional de Serviços e a Programação Geral de Ações e Serviços de Saúde, entre outros elementos que tem por objetivo a implementação de estratégias que permitam a construção de cenários regionais de atenção à saúde (BRASIL, 2011a).

Entretanto, o estudo evidencia que os gestores municipais desconhecem as possibilidades de avanço na regionalização, integração e responsabilidade solidária previstas no COAP e que este instrumento foi pouco difundido e discutido, de forma que não houve participação significativa dos gestores municipais na construção dos diagnósticos para sua implantação, processo este que foi interrompido e esquecido ao longo dos últimos anos.

Outro aspecto que impede a progressão de novas ferramentas para a articulação entre entes federativos, evidenciado por meio deste estudo, é a rotatividade e renovação de grupos políticos nos pequenos territórios. Os resultados mostram que, devido ao processo eletivo, a renovação não apenas do prefeito municipal, bem como do gestor de saúde e também de suas equipes técnicas, mostra aspectos significativos que dificultam as relações federativas. Esses aspectos fazem com que as políticas públicas assumam validade de curta duração e sejam reformuladas constantemente.

A cada mudança de gestão, a gente sente um "pá", uma freada, porque vêm novas cabeças e não é só o secretário, a gente fala de prefeito também, ele tem as ideias dele e a hora que chega lá não é a nossa realidade, aí você não consegue deslanchar. (A02). 
Visto que esses fatores citados dificultam a continuidade no planejamento e o aprofundamento nas necessidades territoriais, O CPS apresenta-se como elemento de fortalecimento das prioridades do território regional, fomentando e promovendo a capacitação dos novos gestores municipais e proporcionando a continuidade nas ações de interesse comum, por meio de consensos entre os pares.

Diante das limitações apresentadas na cooperação entre gestores e na execução de programas por meio de consensos, considerando o ponto de vista econômico, Olson (1999) considera que as organizações são grupos de interesses que podem desempenhar importantes funções sociais, quando da existência de interesses em comum. Ele ressalta que há assimetria nos níveis de interesse entre os membros do grupo, o que poderá incorrer em uma relação de exploração entre pares. Porém, aponta que ainda que existam interesses individuais, pode-se promover a satisfação de seus membros por meio do impulsionamento da ação coletiva. Com isso, o CPS age também como agente neutralizador de interesses de origem estritamente individualistas, apontando para o coletivo como finalidade para suas iniciativas.

Em consideração ao processo de regionalização em saúde, o estudo mostra que, embora os municípios com maior densidade demográfica e capacidade de oferta de ações e serviços tenham assumido responsabilidades teóricas e concretas de maneira solidária junto aos seus pares - as pequenas localidades -, há evidências de desequilíbrio na distribuição da oferta de serviços entre os municípios da região, inviabilizando o avanço das pequenas localidades e, em algumas situações, "prejudicando os municípios pequenos" (A04).

Esse cenário apresentado contrapõe-se às responsabilidades junto às ações de gestão solidárias e de cooperação que os grandes centros assumiram ao longo da história de construção do SUS, uma vez que estes encontraram inúmeros desafios para o desenvolvimento local e naturalmente direcionaram suas ações de gestão para suas necessidades individuais, em detrimento do coletivo regional.

Por outro lado, os municípios com menor densidade demográfica encontram-se em desvantagem para a tomada de decisões, considerando a limitação técnica de suas equipes, o número limitado de profissionais capacitados para atuação na gestão, os interesses distintos entre gestores de saúde e seus prefeitos, o que paralisa a tomada de decisões e a participação efetiva dos pequenos municípios nas instâncias de relação federativa.

O presente estudo mostra que essas limitações no contexto da gestão regional fizeram com que o CPS localizado no território estudado fosse desafiado a tornar-se agente de fomento para o equilíbrio nas relações entre os municípios, qualquer que seja sua condição de gestão. Diante disso, o CPS foi levado à reflexão técnica e tomou iniciativas de gestão para atender ao interesse coletivo, tais como a implantação de uma escola de saúde para qualificação do manejo clínico, a instalação de uma unidade de regulação assistencial, além da representatividade política para captação de recursos originados das esferas estadual e federal, para atenção aos interesses da região.

Nesse sentido, a Carta de Ottawa, publicada como produto da $1^{\text {a }}$ Conferência Internacional para a Promoção da Saúde realizada em 1986 no Canadá, refere-se à equidade como um dos pré-requisitos para conquista da saúde almejada para todas as pessoas no ano 2000 e trata de um sistema de saúde sensível aos que mais 
necessitam (PAIM, 2008; FERREIRA JR; BUSS, 2002). Constata-se que as ações de regulação assistencial instituídas por meio do consórcio evidenciam que há meios viáveis para implantação de estratégias coletivas, com uma prática cooperativa e solidária, que confere benefícios aos seus entes.

Ademais, a partir do modelo referido no estudo, apresentaram-se evidências de que o financiamento do CPS da região se dá por meio de contribuição fixa para todos os entes, sem que a participação seja quotizada. Esse sistema independe da utilização e não incorre em ônus financeiro adicional para qualquer dos entes consorciados diante da ampliação ou redução da oferta diante de suas necessidades, para manutenção de atividades comuns aos entes consorciados. Esse modelo ressalta que o consórcio promove a defesa de uma política de interesse coletivo, que não permite privilégios estritamente individuais.

Todas estas atividades inerentes à atuação do consórcio no território são reconhecidas por sua eficiência pelos gestores municipais de saúde, sujeitos deste estudo, e apontadas como fundamentais para a organização do acesso no território regional. Os atores ressaltam ainda o aspecto da transparência e livre acesso à informação, como benefício aos entes consorciados, conferindo segurança aos entes públicos. Além disso, apresenta-se uma maior facilidade no entendimento por parte dos municípios acerca das rotinas de trabalho desenvolvidas pelo consórcio, fomentando um status de cooperação intermunicipal, o que suprimiu o cenário de competição entre os atores políticos e técnicos que participam desse processo.

Ressalta-se, portanto, que a atuação do CPS é bem vista e reconhecida pelos entes consorciados, em especial aos municípios sede de microrregião de saúde e às pequenas localidades, que apontam que a atuação do consórcio fortalece o processo de regionalização em saúde.

Outro aspecto apontado é a atuação do consórcio em ações que desoneram financeiramente o ente municipal que se vê com poucas alternativas para cobertura de suas lacunas assistenciais, em especial as pequenas localidades.

As características basilares dos consórcios públicos de saúde trazem elementos importantes para a construção da equidade entre os pares, no processo de planejamento, na eleição de prioridades em saúde e na tomada de decisões, o que justifica a introdução dos consórcios na relação federativa. Ademais, Neves e Ribeiro (2006) citam os consórcios como sendo mecanismos de governança regional e ressaltam o ineditismo da utilização de consórcios no governo regional.

Os resultados do estudo, portanto, ressaltam que a ação consorciada é entendida não apenas como a de um ente provido de natureza jurídica própria, uma instituição tangencial ou uma nova instância, mas como um espaço para execução da ação coletiva, que congrega os gestores municipais a interagirem como protagonistas diante do jogo social, mediados por uma rede que os fortalece no cumprimento de suas atribuições, para o fortalecimento do federalismo (OLSON, 1999; MELUCCI, 1989; MATUS, 2005).

Nesse sentido, os consórcios se inserem no contexto da relação federativa, uma vez que congregam entes públicos do executivo, de forma que a participação dos consórcios públicos no âmbito das políticas de saúde é subordinada à deliberação de seus entes consorciados. Dessa forma, Endlich (2017) aponta que os consórcios surgem como agentes que viabilizam novos papéis para a gestão municipal. Essas conquistas potencializam a força política e a capacidade técnica 
regional por meio da gestão conjunta, o que possibilita a tomada de decisões entre pares no âmbito da construção de políticas públicas de saúde.

Com isso, as experiências exitosas de cooperação intermunicipal conferem aos territórios regionais o desenvolvimento econômico, a racionalização e a otimização dos recursos e ganho de escala, além da recuperação de uma dinâmica demográfica positiva, evitando a migração territorial para grandes centros e o favorecimento da multiplicidade interacional entre os entes federativos. Essas iniciativas resultam em melhor qualidade de vida para as pessoas. Essas conquistas potencializam a força política e a capacidade técnica regional por meio da gestão conjunta, possibilitando tomada de decisões entre pares no âmbito da construção de políticas públicas (ENDLICH, 2017).

Entretanto, Melucci (1996) ressalta que não se deve cooperar quando se trata de fortalecer o sistema de dominação, mas para fomentar a equidade. Assim, o CPS pode desconstruir o cenário de competição, propondo ações comuns, com vistas ao fortalecimento das relações federativas no âmbito da saúde.

Nesse sentido, Abrúcio e Soares (2001) apontam que, para que sejam reforçados os laços interfederativos, torna-se necessário o equilíbrio entre a cooperação e a competição, por meio das redes federativas. Dessa forma, é possível a manutenção do pluralismo e da autonomia dos entes, fortalecendo o federalismo. Percebe-se que, embora os consórcios no Brasil tenham se constituído inicialmente a partir da soma de interesses individuais, vislumbra-se a possibilidade de orientação e de organização social entre os entes federativos por meio dos CPSs.

\section{Considerações Finais}

A subjetividade da natureza das relações entre gestores de saúde, nas quais se baseia o discurso empregado nas instâncias de relação, que, por sua vez, dão suporte à tomada de decisões, é que se verifica que as relações de dependência constituem-se como linha indelével condutora desses espaços.

É premente a necessidade de construção de um cenário de cooperação intermunicipal no intuito de conferir identidade aos territórios regionais em todo País e, conforme evidenciado no presente estudo, o CPS é estratégico tanto na articulação como no fortalecimento desses territórios, por meio do fortalecimento dos entes municipais.

Além disso, o estudo aponta para o consórcio como um meritório arranjo organizativo no papel de articulador da atuação do gestor municipal, fomentando o processo de planejamento e gestão em saúde, identifica-se que a potencialidade para a participação e a horizontalidade sejam fatores significativos no ordenamento da ação coletiva.

E nesse contexto, o consórcio pode configurar-se como uma ferramenta para a constituição da ação coletiva, com vistas à construção de uma identidade regional de interesse coletivo, por meio de ações de empoderamento dos entes municipais, sob enfoque técnico, político e administrativo. 


\section{REFERÊNCIAS}

BRASIL. O Ano da Saúde no Brasil. Ações e Metas Prioritárias. Ministério da Saúde. Brasília, 1997a.

. Constituição da República Federativa do Brasil. Promulgada em 05 de outubro de 1988. Diário Oficial da União. Brasília, 1988.

. Decreto Federal $n^{\circ} 6.017$ de 17 de janeiro de 2007. Diário Oficial da União. Brasília, 2007.

. Decreto n $^{\circ}$ 7.508, de 28 de junho de 2011. Diário Oficial da União. Brasília, $2011 a$.

. HumanizaSUS: documento base para gestores e trabalhadores do SUS. Núcleo Técnico da Política Nacional de Humanização. Secretaria de Atenção à Saúde. Ministério da Saúde. Brasília: Ministério da Saúde, 2006.

. Lei Federal n $^{\circ} 11.107$ de 06 de abril de 2005. Diário Oficial da União. Brasília, 2005 .

- Ministério da Saúde. $O$ consórcio e a gestão municipal em saúde. Brasília: Ministério da Saúde, 1997b.

. Perfil dos Municípios Brasileiros - 2011. Tabela 18. IBGE. Brasília, 2011b.

. Resolução CNS nº 466 de 12 de dezembro de 2012. Ministério da Saúde. Diário Oficial da União. Brasília, 2012.

ABRUCIO, F.L.; SOARES, M.M. Redes federativas no Brasil: cooperação

intermunicipal no Grande ABC. Fundação Konrad Adenauer. São Paulo, 2001.

ANDRADE, S.K.A.V. Atuação dos gestores de saúde no âmbito da relação federativa e da ação consorciada. Dissertação (Programa de Pós Graduação em Saúde Coletiva) - Universidade Estadual de Londrina, Londrina, 2018.

ARRETCHE, M. Federalismo e políticas sociais no Brasil: problemas de coordenação e autonomia. São Paulo Perspec., São Paulo, v. 18, n. 2, p. 17-26, June 2004.

BAKHTIN, M. (VOLOCHÍNOV) (1929) Marxismo e filosofia da linguagem. 3. ed. São Paulo: Hucitec, 1986.

CARVALHO, B.G., CORDONI JR, L., SOUZA, R.K.T., MARTIN, G.B., NICOLETTO, S.C.S. A organização do Sistema de Saúde no Brasil. In: Andrade et al. Bases da Saúde Coletiva. 2 ed. rev e ampl. Londrina: Eduel, 2017. p.47-92. 
CORDONI JR., Luiz. Medicina comunitária: emergência e desenvolvimento na sociedade brasileira. 1979. 110f. Dissertação (Mestrado em Medicina Preventiva) Faculdade de Medicina, Universidade de São Paulo, 1979.

CUNHA, Augusto Paulo Guimarães. Representações sociais e organização do poder político: a engenharia social do federalismo no Brasil Império. 2001. 109f. Dissertação (Mestrado em Administração Pública) - Fundação Getúlio Vargas, Rio de Janeiro: EBAPEFGV, 2001.

ENDLICH, A.M. Cooperações intermunicipais: alguns aportes. Maringá: PGE-UEM, 2017.

FERREIRA JR, BUSS P. Atenção primária e promoção da saúde. In: Ministério da Saúde (BR). As cartas da promoção da saúde. Brasília: Ministério da Saúde, 2002. p.7-18.

FLEURY, S. Democracia, descentralização e desenvolvimento: Brasil e Espanha. Rio de Janeiro: Editora FGV, 2006.

HARMAN, G. Intergovernmental relations: federal systems. In: HAWKESWORTH, M. e KOGAN, M. (eds.). Encyclopedia of government and politics. London, Routledge, p.336-350, 1992.

HOCHMAN, G. Reformas, instituições e políticas de saúde no Brasil (1930-1945). Educar. n. 25, p. 127-141. Curitiba, 2005.

LIMA, A.P.G. Os Consórcios Intermunicipais de Saúde e o Sistema Único de Saúde. Cad. Saúde Pública, Rio de Janeiro, v. 16, n. 4, p. 985-996, Dec. 2000.

LIMA, L.D.; VIANA, A.L.D.; MACHADO, C.V. et al. Regionalização e acesso à saúde nos estados brasileiros: condicionantes históricos e político-institucionais. Ciência \& Saúde Coletiva, 17(11):2881-2892, 2012.

LUZ, M.T.. Notas sobre as políticas de saúde no Brasil de "transição democrática": anos 80. Physis, v.1, n. 1, p. 77-96, 1991.

MARTINS, J.; BICUDO, M. A.V. A pesquisa qualitativa em psicologia: fundamentos e recursos básicos. São Paulo: Centauro, 2003.

MATUS, C. Teoria do jogo social. Salud Colectiva, Buenos Aires, v. 3, n. 1, p. 81- 91, 2005.

MELUCCI, A. Challenging codes: Collective action in the information age. Cambridge University Press, 1996.

MELUCCI, A. Um objetivo para os movimentos sociais. CEDEC, $n^{\circ} 17$, jun., Lua Nova. São Paulo, pp. 49-66, 1989. 
MENDES, EV. Distritos sanitários: processo social de mudanças nas práticas sanitárias para Sistema Único de Saúde. São Paulo: Editora Hucitec/Rio de Janeiro: ABRASCO; 1993.

NEVES J.A, RIBEIRO, J.M. Consórcios de saúde: estudo de caso exitoso. Cad Saude Publica. 2006;22(10):2207-17. DOI: 10.1590/S0102-311X2006001000027

NICOLETTO, Sônia Cristina Stefano. As comissões Intergestores regionais e a gestão interfederativa no norte do Paraná, 2011 a 2013. 2015. 18of. Tese (Programa de Pós Graduação em Saúde Coletiva) Universidade Estadual de Londrina, Londrina, 2015.

OLSON, M. A lógica da ação coletiva: os benefícios públicos e uma teoria dos grupos sociais. São Paulo: EdUSP, 1999.

PAIM, J.S. Período FHC. In: Reforma sanitária brasileira: contribuição para a compreensão e crítica [online]. Salvador: EDUFBA; Rio de Janeiro: FIOCRUZ, pp. 203-239, 2008.

PINAFO, E. et al. Gestor de município de pequeno porte no estado do Paraná: perfil, funções e conhecimento sobre os instrumentos de gestão. Espaço para a Saúde: Revista de Saúde Pública do Paraná, Londrina, v. 17, n. 1, p. 130-137, jul. 2016.

PRATES, A.M.Q. Federalismo no Brasil: os consórcios públicos intermunicipais no período recente. 2012. 210f. Tese (doutorado) Universidade Estadual de Campinas/Instituto de Economia, Campinas/SP, 2012b.

PRATES, A.M.Q. Os consórcios públicos municipais no Brasil e a experiência europeia: alguns apontamentos para o desenvolvimento local. In: CONGRESSO CONSAD DE GESTÃO PÚBLICA, III. Brasília, 2002a.

RABAT, M.N. A federação: centralização e descentralização do poder político no Brasil. Câmara dos Deputados. Brasília. 2002

ROCHA, C.V. A cooperação federativa e a política de saúde: o caso dos Consórcios Intermunicipais de Saúde no estado do Paraná. Cadernos Metrópole. 2016. 18(36), 377-399. https://dx.doi.org/10.1590/2236-9996.2016-3604

ROCHA, C.V; FARIA, C.A.P. Cooperação intermunicipal, reterritorialização da gestão pública e provisão de bens e serviços sociais no Brasil contemporâneo: a experiência dos Consórcios de Saúde de Minas Gerais. Cadernos Metrópole, N. 11, pp. $73-105,1^{\circ}$ sem. 2004

SANTOS, L.; Campos, GWS. SUS Brasil: a região de saúde como caminho. Saude soc., Jun 2015, vol.24, no.2, p.438-446. ISSN 0104-1290 
SCHOLZE, A.S.; DUARTE JUNIOR, C.F.; FLORES E SILVA, Y. Trabalho em saúde e a implantação do acolhimento na atenção primária à saúde: afeto, empatia ou alteridade? Interface (Botucatu), Botucatu , v. 13, n. 31, p. 303-314, Dec. 2009.

SEGATO, R.L. Antropologia e direitos humanos: alteridade e ética no movimento de expansão dos direitos universais. Mana, Rio de Janeiro, v. 12, n. 1, p. 207-236, Apr. 2006.

SOUZA, C. Federalismo, desenho constitucional e instituições federativas no Brasil pós-1988. Rev. Sociol. Polit., Curitiba n.24, p.105-121, junho 2005.

SROUR, R.H. Poder, cultura e ética nas organizações. 6 ed. Rio de Janeiro: Campus, 1998.

VAZ, J. C. Consórcios Intermunicipais. Dicas Polis Ildesfes: ação administrativa ideias para a ação municipal. 1997.

Fernanda Freitas Mendonça. Graduação em Enfermagem pela Universidade Estadual de Maringá (2004). Especialista, mestre e doutora em Saúde Coletiva pela Universidade Estadual de Londrina. Tem experiência na área de Enfermagem, com ênfase em Enfermagem de Saúde Pública. Docente do Departamento de Ciências da Saúde na Universidade Estadual de Londrina. fernanda0683@gmail.com

Silvia Karla Azevedo Vieira Andrade. Possui graduação em Letras - Inglês pela Universidade Estadual de Londrina. Tem experiência na área de Saúde Coletiva. Atuou na função técnica e gerencial de apoio à gestão municipal, nas áreas de controle e avaliação, auditoria, programação e planejamento em sáude e regulação assistencial, no período de 1998 a 2010. Atuou na direção técnica de Planejamento e Atenção à Sáude do CISMEPAR, consórcio público de saúde da região do Médio Paranapanema de julho/2010 a março/2018. É mestre em Saúde Coletiva pela Universidade Estadual de Londrina. É doutoranda em Saúde Coletiva na Universidade Estadual de Londrina.silviakarla77@gmail.com 